\title{
A VISCOSSUPLEMENTAÇÃO COMO OPÇÃO TERAPÊUTICA PARA AS ALTERAÇÕES DEGENERATIVAS DA ATM
}

Eduardo MACHADO, Paulo Afonso CUNALI, Daniel BONOTTO

Dentre as Disfunções Temporomandibulares (DTM) articulares, as incoordenações do complexo cabeça da mandíbula/disco articular decorrem do colapso da função normal do disco sobre a cabeça da mandíbula pela incompetência dos ligamentos colaterais do disco e lâmina retrodiscal inferior, sendo exemplos dessa situação os deslocamentos de disco com e sem redução, que podem estar associadas a alterações inflamatórias ou degenerativas da articulação temporomandibular (ATM). Como protocolo inicial de tratamento opta-se por terapias reversíveis e pouco invasivas, porém em algumas situações devido às alterações estruturais presentes o tratamento conservador torna-se pouco responsivo. Nessas situações, a viscossuplementação aparece como alternativa de tratamento para as alterações internas da ATM. Estudos em animais, em articulações como joelhos e ombros, e na ATM procuraram avaliar os efeitos da injeção intra-articular de hialuronato de sódio. Esse trabalho tem como objetivo através de uma revisão crítica de literatura baseada em estudos clínicos randomizados (RCTs) e meta-análises, e da apresentação de um caso clínico, com acompanhamento de 12 meses, de uma paciente que apresentava osteoartrose e alterações degenerativas da ATM, discutir a técnica e a efetividade da viscossuplementação da ATM. 